\title{
Digitalization of the financial subsystem of industrial enterprise: points of implementation
}

\author{
Nataliia Bieliaieva ${ }^{1}$, Olena Sova $^{2, *}$, Tetiana Ganushchak $^{1}$, Olena Zhuk $^{1}$, and Olena \\ Matusova $^{1}$ \\ ${ }^{1}$ Kyiv National University of Trade and Economics, 19 Kyoto St., 02156 Kyiv, Ukraine \\ ${ }^{2}$ National University of Life and Environmental Sciences of Ukraine, 15 Heroiv Oborony St., 03041 \\ Kyiv, Ukraine
}

\begin{abstract}
The article deals with formulation the measures for digitalization of the financial system of industrial enterprises taking into account the management points of its implementation. The article provides an understanding of digitalization. It is analyzed current scientific researchers in this field. It is established that modernization of the financial sphere of an industrial enterprise in the aspect of adaptation to the information economy and digitalization process. It is proved that the executive's digitalization project creation requires the definition and reevaluating of structures, patterns, techniques, benefits and computerized processes, development strategy and comparing corporate culture with correspondence of instruments between all administration units for speedy reaction on changes. It is analyzed the value creation stages based on core product. Identified elements indicate the directions that need to be implemented at the enterprise for its stable functioning.
\end{abstract}

\section{Introduction}

Digitalization is a deep business transformation that means the use of digital technology to optimize business processes of the company, increase its productivity and improve the customer experience. Especially nowadays due to all over the world pandemic situation, digitalization comes worldwide. Even the key direction of the World Economic Forum in Davos is the fourth industrial revolution - Industry 4.0. Digital technologies should also be a driving force for innovations in the Ukrainian economic system [1]. It is understandable that when we are talking about digitalization of business, it means that company needs to think about possibility of digitalization of each business process at the enterprise. However, sometimes it is not so easy to do according to the company's field of activity (trade, service, manufacturing), legislative norms, possibility of digitalization in general, including financial capacities of the company.

Talking about industrial enterprises we understand that it could be also hands manufacturing (for instance, it is common in such countries as India, Ukraine, China), but as a rule it is more about a small business.

Corresponding author: sovy@ukr.net 
If we are talking about industry, it means that there work many employees (if we are not talking about automated cycle of manufacturing). Moreover, as soon as we have many people to be managed, it is required to optimize all routine processes. So digitalization can handle that. Moreover, there exist many automated systems that can help to manage employee's activity, marketing sphere etc. (CRM, SAP, ORACLE, Bitrix etc). Information systems based on digitalization of not only production, but also society as a whole will become an integrator of breakthrough technologies, when industrial enterprises become just one of the platforms integrated into modern industrial development. Nevertheless, there is one item that is not highlighted so much in researches - digitalization of the financial subsystem of the enterprise. Yes, digital finance and financial inclusion has some advantages to financial services users, digital finance providers, governments and the economy in general [2]. Nevertheless, a number of issues still persist which if get solution can make digital finance work better for industrial enterprises. As nowadays, they are not as popular as trading companies are.

However, digitalization of the financial system not means just using digital finance. According to Gomber P., Koch J., M. Siering [3], digital finance encompasses a magnitude of new financial products, financial businesses, finance-related software, and novel forms of customer communication and interaction - delivered by FinTech companies and innovative financial service providers. Thus, the relevance of the study of existing scientific base in this direction is quite important.

The purpose of the article is to formulate a framework of actions for digitalization of the financial system of industrial enterprises on the base of researching managerial points of its implementation.

\section{Literature review}

A number of scientific works related to the aspects of digitalization give us a good background for understanding that it is still important and there is no one common way to be successful for the organization all the time. Especially nowadays when it is difficult to predict next steps of governments due to world pandemic. Still it is understandable that without digitalization most of businesses can die under such conditions of business conduction. Deserves the approval of the author's position E. Pimenova [4] that the key indicator of a high level of digitalization is the adoption of management decisions based on objective business analysis data, as well as the use of technological tools to improve the stability of enterprise functioning. The author also considers the need for a comprehensive assessment of sustainability not only from the financial point of view, but also from the point of view of the environmental and social significance of this issue that is also sensitive for industrial enterprises. However, incumbent manufacturing firms tend to be more oriented toward improving their process efficiency through Industry 4.0 [5].

For our point of view, it is also important to provide a complex embedded system analysis of early warning systems and their development and use in a variety of environments, especially in the economic and financial fields [6] while digitalization processes as it can increase the sustainability of the enterprise.

Such scientists as O. Akymenko, A. Petrovska, M. Zholobetska, and D. Skrytskyi [7] have made a good research about the state of the digital transformation of Ukrainian enterprises. They also provide transformation directions of the value chain in which new digital technologies can be used. More close to industrial enterprises research are A. Sakhno, I.Salkova, A. Broyaka, N. Priamukhina [8]. Their research connected with developing methodological bases for sustainable development of agrarian production in conditions of digitalization. For this it was developed a conceptual model of agro-digital cooperation platform and balancing of agricultural production. 
Digitalization in industrial enterprises can be viewed from two sides [9]:

- on the one hand, it is the production of new products that did not exist before (including the production of digital technologies themselves). Such types of production are initially created on the technological basis corresponding to the modern development level of science and technology (in fact - to a new technological order which doesn't have any common and by everybody accepted name at present);

- on the other hand, it is the production of goods familiar to the market for a long time but on a new technological basis with the introduction of new methods in the existing production, improvement/modernization of existing production processes. The introduction of digital technologies leads to a fundamentally new business structure and organization of the business processes that can be observed in different areas.

So, there are lots of researches about digitalization, but only some of them devoted to the digitalization of the financial system of industrial enterprise.

\section{Material and methods}

The results are based on modern scientific researches and financial data for digitalization implementation process. System analysis is used for subject research understanding, i.e. what is digitalization and how it can influence existing business models of an enterprise; what is the role of digitalization of the financial subsystem of an industrial enterprise under nowadays circumstances. Synthesis is used to make a number of conclusions aimed to build a clear concept of the cause-and-effect relationships between digitalization and new business models. Causal analysis is used for the network created to capture the links and the influence of new business models implementation. Using analysis, a logical sequence of factors and their interrelationships was established within the entire process of enterprise management for digitalization implementation process. Identified elements indicate the directions that need to be implemented at the enterprise for successful implementation process.

\section{Results and discussion}

Digital transformation can be named as the ideal response to the threats of digital disruption that puts pressure on incumbent organizations to respond to the changes that digital technologies have cause and will continue to cause. Anyway, digitalization it is a "must have" for all organizations which want to be successful nowadays [10]. It is aimed to make it easier and faster the work with big data bases, to provide optimization of all types of enterprises activity (operational, financial, investments etc), to improve communications as with clients, suppliers and partners, either with all institutions of external environment, to form new approaches of interactions inside an organization (between departments, employees, management system in general), to provide new forms of business economy (network and virtual economy).

As we have mentioned earlier, digitalization affected service and banking sectors more than the production enterprises, but nowadays it is hard to talk about their further development without the use of digital technologies, especially not only in the conditions of fierce competition for consumers and limited resources, but due to the pandemic restrictions all over the world connected with COVID-19 [9]. The task of one other research was to find out an optimal variant of bank resources formation. It was conducted in accordance with the analysis of the banking sector and strategies of deposit portfolios formation by specific commercial banks. "When forming a deposit policy of a commercial bank, the top- 
management has set certain goals - increasing the volume of the resource base, minimizing the costs of attracting resources, maintaining the regulatory level of liquidity" [11].

However, simultaneously with the increasing of the use of digital technologies has increased the pervasiveness and scale of cyber-attacks that pose significant threat to the security and privacy of customers' data on digital channels. In such situation of cyber risks awareness regulators should rethink about balance between efficiency and security in financial services at least [2]. In this way, we also need to understand that we are talking about digitalization, but not digitization. If digitization firstly aimed at improvement of exciting business processes, so digitalization gives an opportunity to get significant breakthrough in business and new competitive advantages. That is why digitalization can be attributed to the 4th industrial revolution, as often named Industry 4.0.

Last decades are characterized with the rapid evolution in the quantity and quality of the available digital technologies, which changes the established ways of business conducting. In the current economic conditions, enterprises must respond in time to changes in the global market. Modern technologies will help prevent the fall of the industry. According to McDonald \& Russel-Jones, digital technologies are shaping the way people live, communicate, consume and work, breaking the barriers of time and space [12]. Furthermore, these advancements are constantly changing the way consumers interact with companies and each other. The potential benefits for an enterprise of becoming fully digital are enormous but such a journey is complicated as multiple challenges have to be addressed [13]. An important step is also the implementation of policies aimed at protecting life and health from the negative effects caused by environmental pollution, achieving a harmonious interaction between society and nature [14]. And it is connected as digitalization helps to decrease the amount of unnecessary typical operations and therefore decrease the level of raw materials for instance. In addition to solving environmental problems, the reconstruction of factories and the modernization of equipment will optimize the costs of manufacturing products and allow the release of new types of products.

It is proved that the executive's digitalization project creation requires the definition and reevaluating of structures, patterns, techniques, benefits and computerized processes, development strategy and comparing corporate culture with correspondence of instruments between all administration units for speedy reaction on changes. We can tell that the execution viability of the board activities and measures for big business the board digitalization, its action and improvement relies upon the chose advanced change innovations, the chance of significant information data clusters framing, their systematic preparing and introduction for specific choices making progressively [15]. Because of this it is better to use Analytical Hierarchy Process - a novel multi-criteria decision-making technique that is employed in identifying the vital critical factors amongst these [16].

The real sector of the economy is least associated with digital. According to popular belief, industrial companies are the least active on social networks, they do not communicate with customers via Internet channels. The websites of most of these companies are not mobile-friendly, and their design has not been updated since the mid2000s.

In June 2019 in Ukraine was developed and signed Manifesto of the new industry of Ukraine by almost 50 associations of industrialists. It is aimed to support exist industry at times of $4^{\text {th }}$ Industrial Revolution and includes three political steps that can stop the process of country's deindustrialization - to pronounce officially that industrial development is one of the tops political priority; to approve Strategy of industrial development focused on creation of a new processing facilities in the national economy, industrial sectors digitalization and infrastructure reconstruction; to create a new position - Deputy Prime Minister for Industrial Policy. That is not too much, but still we don't have any visible steps in this direction. 
But it is required - with governmental support it's easier to make all such big changes that concerned to the whole industry. Also we can't be silent about the initiatives implementation that are planned in the Digital Agenda for Ukraine (in particular, within Industry 4.0 it was laid down as the creation of roadmaps for individual industries and enterprises digitization, so the transition to new digital standards) should ensure comprehensive digitalization of Ukrainian industry and economy. The result is zero.

Simultaneously, we cannot take away the importance of traditional credit and financial institutions in mediating financial transactions between business participants, even if we are talking about industrial enterprises (as they still proceed payments), and highlight their strengthening in the implementation of digital payments between counterparties [17]. However, digital solutions and new technologies offer great potential to overcome massive development challenge [18].

Modernization of the industrial sphere of an industrial enterprise in the aspect of adaptation to the information economy and digitalization process can be separated by the following general measures:

- robotization of production and technological operations;

- automation of control of production and technological operations;

- use of more efficient equipment;

- improvement of production operations;

- automation of planning and provision of production tasks.

The spread of industry-wide businesses catches team structure as an operational model, emphasizing the need to work collaboratively and communicate effectively. Anyway, they must combine it with the work according to exist regulations and standards.

It is really difficult for large industrial giants from traditional sectors of the economy to go digital simply because of their scale. This situation is typical not only for Ukraine, but also for developed economies. For example, in the United States, the least digitalized industries are agriculture, construction, hospitality and healthcare, according to a McKinsey report. Low indicators of digital use - also in the oil, mining, chemical and pharmaceutical industries, etc. It turns out that the industries with the highest indicators in terms of GDP and employment are the least "digitized" (Fig. 1).
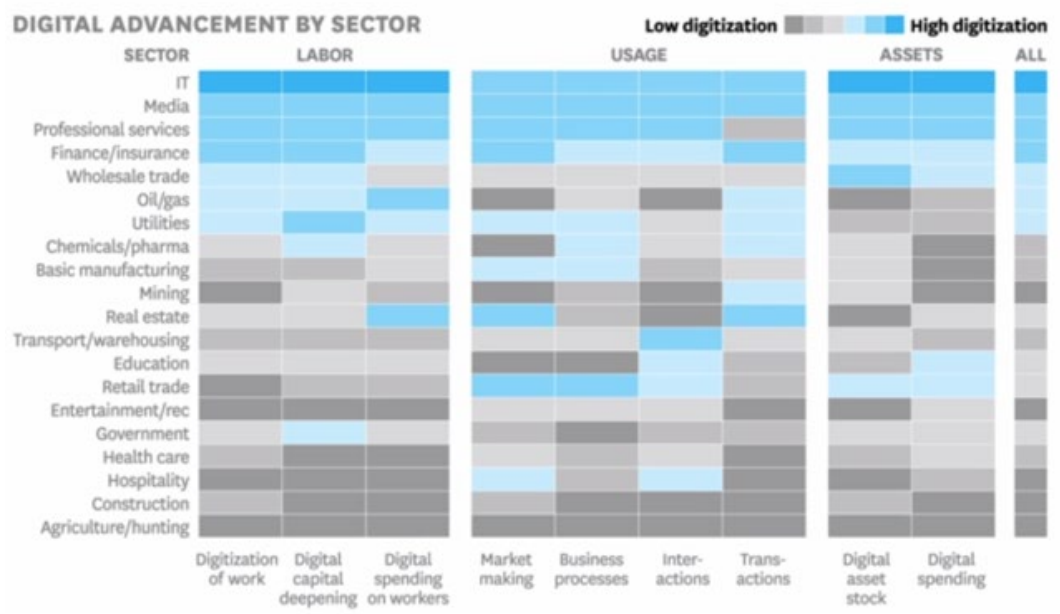

Fig. 1. Levels of digitalization by sectors. 
Therefore, digitalization changes the product creation processes of an industrial enterprise in all spheres: product design, production, logistics, marketing and sales, service maintenance, security, staff. And even business processes are digitized - that means the processes of operating a digital product become digital themselves. One of the best examples - the document flow of an enterprise: many documents have become digital.

To work with digital documents participants of business processes should use special applications that require coordination of users, special applications of software and data. However, purchasing and application of different software is costly for the enterprise, it requires both capital and current costs. There is a good background about all these in the scientific research of A. Chudaeva, V. Mantulenko, P. Zhelev, R. Vanickova [9]. In modern conditions, companies seek to increase productivity not by increasing output, but by optimizing the structure of the enterprise and the number of staff. Production automation has become an ongoing process. Digital technologies are reducing the number of middleskilled workers.

Still, what we can say about how digitalization influence financial system of industrial enterprise? What to do to rationalize costs while spending on new technology and equipment?

One of the answers - smart financing - it's financing solutions (software) that help manufacturers upgrade, digitalize and stay competitive - enabling them to meet the growing demand for customization, productivity and flexibility in the "new normal" (Table 1). Companies in multiple sectors are incorporating information technology partners to gain digital capabilities, improve their operations, and offer new value propositions. The digitalization deployment in well-established companies from traditional sectors enables the creation of specific strategic alliances (concentric) with IT providers [19, 20]. And it's important to remember that information systems strategy must be aligned with the business strategy. Therefore, to ensure alignment between information systems strategy with business strategy, we need a good strategic planning of information systems in order to achieve organization goals [21].

It should be noted that the effective organization of management of the financial subsystem of the enterprise depends on providing the financial subsystem with timely, high-quality, truthful information coming from its individual elements and subsystems. The managerial information can be considered as the basis for implementation of system organized phenomena which provide development of instruments, methods and strategies of management $[22,23]$. Industrial companies are moving towards greater digital value creation, from augmented products to serving digital ecosystems (Table 1).

Table 1. Value Creation Stages Based on Core Product.

\begin{tabular}{|c|l|l|}
\hline No & \multicolumn{1}{|c|}{ Stage } & \multicolumn{1}{c|}{ Focus on } \\
\hline 1 & $\begin{array}{l}\text { Augmented Digital Product } \\
\text { Player }\end{array}$ & $\begin{array}{l}\text { Focus on products with digital features like sensors or } \\
\text { communication devices }\end{array}$ \\
\hline 2 & $\begin{array}{l}\text { Complete Solution / Service } \\
\text { Provider }\end{array}$ & $\begin{array}{l}\text { Focus on digital products and data-based services. } \\
\text { Which provide a complete solution for the customer }\end{array}$ \\
\hline 3 & $\begin{array}{l}\text { Data Analytics, Content and } \\
\text { Platform Integrator }\end{array}$ & $\begin{array}{l}\text { Focus on data analytics and data-based services; access } \\
\text { to customers via a dedicated (online) platform }\end{array}$ \\
\hline 4 & $\begin{array}{l}\text { Integrated Digital Ecosystem } \\
\text { Provider }\end{array}$ & $\begin{array}{l}\text { Integration of third-party partner or competitor products } \\
\text { and control systems in a complete customer ecosystem }\end{array}$ \\
\hline
\end{tabular}

Digitalization includes the formation of a multi-channel system of communication with customers (call center, messengers, social networks, own site), the development of communication infrastructure with partners (API-system, integration of partner companies), collection, sorting, analysis and evaluation of data for decision making (1C, CRM-system, ERP system, Bigdata technologies, agile development), introduction of new digital 
technologies (Softpoint, PERFEXPERT) and other digital solutions. So, if we are talking about digitalization, duration of the digital transformation depends firstly on the scope of the business. Nevertheless, readiness of the organization itself for deep change also influence on all duration process. As a rule, it is used a wide ecosystem of global vendors, including Microsoft solutions, to unite manufacturing divisions, open wider opportunities for employees to communicate and interact, and also optimize their day-to-day operations.

So we can talk about digitalization tools and their implementation as: data processing technologies: machines help to process data and make efficient but non-obvious decisions; automation; cloud technologies: the power of a cloud-based IT system scales quickly, so an experiment can be performed to test a business model of any complexity without risky capital investments.

The finances of the enterprise are profit, incomes and expenses, net cash flow circulating both inside and outside the enterprise. Enterprise financial management automation includes financial accounting automation, financial analysis automation and enterprise financial planning automation, i.e. a full range of measures based on economic and mathematical methods and performance indicators. Such a program for automating the financial activities of a company can be formulated as the Universal Financial Accounting System (UFAS), in which there is a huge range of opportunities for systematization, design, collection, processing and analysis of financial information. After own settings automation, the program can distribute a part of the income from the company's activities to the necessary planned costs, and display the company's profit.

Automation of financial activities will help to relieve company's employees from routine work, thereby reducing various administrative costs, increasing the efficiency of each employee and the ability to make various management decisions. Actions such as settlement of payments with suppliers and contractors, calculation of taxes on profits and all other mandatory payments to the budget, payroll, payment of dividends and many other actions with finances can become automatic with the help of the correct program and individual UFAS settings. The program for automating the financial activities of the UFAS analyzes the enterprise after collecting financial accounting data, displays all the reports necessary for both government agencies and founders, directors, financial department, top managers. Thanks to reporting, manager can draw up a further development strategy for the organization, see all the flaws and weaknesses of the business, and make a prompt decision.

Below is a short list of the UFAS solutions (Table 2). It's a basic one, of course, the list of possibilities may vary depending on the configuration of the developed software.

Table 2. Basic Universal Financial Accounting System Solutions.

\begin{tabular}{|l|l|}
\hline \multicolumn{1}{|c|}{ Software directions } & \multicolumn{1}{c|}{ Solutions } \\
\hline The income accounting program & $\begin{array}{l}\text { helps to establish the financial management of the } \\
\text { company }\end{array}$ \\
\hline The payment accounting system & can record all payments for any counterparty and by date \\
\hline Cash flow management software & can be customized for each user \\
\hline The activity report & $\begin{array}{l}\text { will allow to see the financial position of the company as a } \\
\text { whole }\end{array}$ \\
\hline $\begin{array}{l}\text { Automation of activities with a } \\
\text { financial management program }\end{array}$ & will allow to fully control many organizational processes \\
\hline Employee motivation & $\begin{array}{l}\text { is feasible on the basis of reporting on the activities of each } \\
\text { employee, provided on the basis of the results of the } \\
\text { program }\end{array}$ \\
\hline The invoicing software & allows to print any financial documents \\
\hline Automation of income and expense & $\begin{array}{l}\text { greatly facilitate the financial accounting of an } \\
\text { organization's funds }\end{array}$ \\
\hline Organization of cash accounting & allows easily track the outflow and inflow of cash \\
\hline
\end{tabular}


Calculations of the basic version of Universal Financial Accounting System implementation are presented in table 3 .

Table 3. Calculations of the Universal Financial Accounting System implementation.

\begin{tabular}{|l|r|r|r|r|}
\hline \multicolumn{1}{|c|}{ Item } & Quantity & $\begin{array}{c}\text { Unit of } \\
\text { measurement }\end{array}$ & Price, USD & \multicolumn{2}{c|}{$\begin{array}{c}\text { Amount, } \\
\text { USD }\end{array}$} \\
\hline Single user program & 1 & pcs & 85 & 85 \\
\hline Additional users & 3 & pers. & 80 & 240 \\
\hline Free hours of technical support & 5 & hour & 0 & 0 \\
\hline $\begin{array}{l}\text { Additional hours of technical } \\
\text { support }\end{array}$ & 0 & hour & 0 & 0 \\
\hline \multicolumn{1}{r|}{ Total } & & & & 325 \\
\hline
\end{tabular}

Best financial software can significantly improve the financial level and efficiency of work, management of personnel resources to achieve goals [24]. Finances always need careful control and accounting, therefore, it can be just single user program, when only one person can use this pogram; or with multiple users. However, for each registered employee, in addition to the login and password, an individual access level will be introduced, which will directly depend on the position and rights held. An exception will be made only by the head of the organization and, if desired, a person trusted by him: they will be provided with access to any information of interest to them, as well as the right to perform any actions. Also, with the help of the financial management application, the manager will be able to see any activity of all employees, which will positively affect the optimization of work. Also, if an employee leaves his workplace, then after a certain time, the UFAS is automatically blocked in order to protect the data of your organization. However, technology is only the part of the digital transformation. New culture and business thinking are faithful companions of successfully implemented projects. Employees which affected by the project or its results should be involved from the beginning. They should be involved, informed, educated, motivated from the beginning and all the way. Perhaps it's even suitable to change their skills, understanding and attitude towards the subject of transformation.

Consider a project for digital transformation of business processes of an enterprise based on the service integrator using the company's universal digital platform. Thus, it is necessary to integrate information technologies into the work of enterprises in order to keep up with the development of the market and keep all business processes under control [25, 26]. Optimization of the enterprise using digital transformation tools implies the solution of the following tasks:

1. Expanding the customer base, increasing the share of commercial orders, that will entail an increase of financial transactions;

2. Reduction of the cost of sales due to self-ordering;

3. Optimization of the warehouse and production management process;

4. Reducing the sales chain and avoiding intermediaries;

5. Build the foundation for the Market Place.

The degree of information technologies implementation primarily depends on the specifics of business processes. Integration of all information and technological resources of the enterprise will help to optimize the costs of human resources, simplify the establishment of contacts with consumers and contractors, and also regulate the management of all production and business processes. Anyway, the main goal of digitalization, the need for which is now much talked about, is not the introduction of new technologies by themselves. Its conceptual task is to globally increase the efficiency of production and business. Thus, the digital transformation of a company is not based on new technologies per se, but on new business models. 


\section{Conclusions}

Digital technologies in business have long been no know-how. Nevertheless, lots of companies continue to operate the old fashioned way, despite a number of obvious advantages that open up after the implementation of IT solutions. The need for a course towards digitalization of the economy was announced at the highest level, calls for the introduction of digital technologies in industry are increasingly heard from the sites of the largest forums. Digitization and technology disruption are changing the shape of our world, transforming society, industries and economies by reinventing traditional business models and creating new ones. The problem statement of transition to the new technologies of organizing the economy and, in particular, its industrial sector deserves unconditional support. The designated vector of innovation development and "digitalization" assumes strategic importance.

Digitalization leads to the emergence of such an opportunity as management of the organization in "real time" (Real Time Enterprise), which allows to receive information immediately, in the mode close to "real time". The basic principles of "digital" management, both at the level of industrial enterprises and at the state level, are the following: data acquisition in real time; economic processes management on the basis of automated big data analysis; high speed of decision making, instant response to changes and interactive environment; orientation towards a specific user, customer life situations as a business process are getting closer thanks to mobile devices and the Internet of things; one-touch solutions; digital ecosystem is understood as a center of synergy among the state, business, and citizens. While it is clear that digital technology will transform most industries, there are a number of challenges that need to be understood. These include factors such as the pace of changing customer expectations, cultural transformation, outdated regulation, and identifying and accessing the right skills, among others. These challenges need to be addressed by industry and government leaders to unlock the substantial benefits digital offers society and industry.

The following advantages of digitalization can be distinguished: optimization and improvement of communications - both internal and external; saving financial and natural resources; saving time and increasing productivity through production automation; optimization of work with a data set; competitive opportunities by improving the customer experience and overall optimization of the workflow. The obtained results show that set of laws and regulations in the digital economy has many gaps and contradictions. Therefore, various initiatives to implement the digital economy in Ukraine are still in the project stage. To implement "digital" transformations, Ukrainian enterprises, small and medium-sized businesses, and industry need to be provided with support, which may include a wide range of activities, from marketing to fiscal and motivational. The result of this activity will be the modernization of the economy, its recovery and competitiveness.

\section{References}

1. Boyko, L., Bieliaieva, N., \& Bay, S. (2020). Problems And Prospects Of Digital Economy Development In Ukraine. International Journal of Advanced Science and Technology, 29(8s), 2322-2328. http://dx.doi.org/10.35940/ijrte.C1038.1183C19

2. Ozili, K. P. (2015). Impact of digital finance on financial inclusion and stability. Borsa Istanbul Review, 18(4), 329-340. https://doi.org/10.1016/j.bir.2017.12.003

3. Gomber, P., Koch, J.A., \& Siering, M. (2017). "Digital Finance and FinTech: current research and future research directions". Journal of Business Economics, 87, 537-580. https://doi.org/10.1007/s11573-017-0852-x 
4. Pimenova, E.M. (2021). Specificity of sustainability assessment for industrial enterprise functioning in the digital economy. Lecture Notes in Networks and Systems, Switzerland, 139, 3-10. https://doi.org/10.1007/978-3-030-53277-2_1

5. Müller, M. J., Buliga, O., Voigt, Kai-Ingo. (2020). "The role of absorptive capacity and innovation strategy in the design of industry 4.0 business Models-A comparison between SMEs and large enterprises". European Management Journal. https://doi.org/10.1016/j.emj.2020.01.002

6. Lin, J. (2021). "Design of enterprise financial early warning model based on complex embedded system". Microprocessors and Microsystems, 80. https://doi.org/10.1016/j.micpro.2020.103532

7. Akymenko, O., Petrovska, A., Zholobetska, M., \& Skrytskyi, D. (2020). Digital development of the economy and its role in improving the international competitiveness of Ukraine. International Journal of Advanced Science and Technology, 29(8s), 22902296. https://doi.org/10.35940/ijrte.C1011.1183C19

8. Sakhno, A., Salkova, I., Broyaka, A., \& Priamukhina, N. (2020). A Methodological analysis for the impact assessment of the digitalisation of economy on agricultural growth. International Journal of Advanced Science and Technology, 29(8s), 242-249. http://sersc.org/journals/index.php/IJAST/article/view/10493/5635

9. Chudaeva, A., Mantulenko, V., Zhelev, P., \& Vanickova, R. (2019). Impact of Digitalizationon the Industrial Enterprises Activities. Problems of Enterprise Development: Theory and Practice: SHS Web of Conferences, 62 . https://doi.org/10.1051/shsconf/20196203003

10. Ilin, I., Levina, A., Borremans, A., \& Kalyazina, S. (2020). Enterprise Architecture Modeling in Digital Transformation Era. International Scientific Conference Energy Management of Municipal Facilities and Sustainable Energy Technologies EMMFT, 2, 124-142. http://dx.doi.org/10.1007/978-3-030-57453-6_11

11. Sova, O. (2018). "Features of deposit products in modern conditions of the banking market of Ukraine". Financial and credit activity: problems of theory and practice, 3(26), 72-80. https://doi.org/10.18371/fcaptp.v3i26.143865

12. Tomchuk, O., Lepetan, I., Zdyrko, N., \& Vasa, L. (2018). "Environmental activities of agricultural enterprises: accounting and analytical support". Economic annals-XXI, 169, 77-83. http://dx.doi.org/10.21003/ea.V169-15

13. Karagiannaki, A., Vergados, G., \& Fouskas, K. (2017). The Impact Of Digital Transformation In The FinancialServices Industry: Insights From An Open Innovation Initiative In Fintech In Greece. MCIS Proceeding. http://aisel.aisnet.org/mcis2017/2

14. Ilchenko, V., Bondarenko, V., Koroliova, O., \& Petrovska, S. (2020). An analysis of digital technology impact on improving the environmental status. International Journal of Advanced Science and Technology, 29(6s), 1087-1093. http://sersc.org/journals/index.php/IJAST/article/view/9192/5078

15. Davydova, O., Kashchena, N., Staverska, T., \& Chmil, H. (2020). Sustainable development of enterprises with digitalization of the economic management. International Journal of Advanced Science and Technology, 29(8s), 2370-2378. http://sersc.org/journals/index.php/IJAST/article/view/14712/7500

16. Khurana, S., Haleem, A., Luthra, S., \& Mannan, B. (2021). "Evaluating critical factors to implement sustainable oriented innovation practices: An analysis ofmicro, small, and medium manufacturing enterprises". Journal of Cleaner Production, 285. https://doi.org/10.1016/j.jclepro.2020.125377 
17. Mikhaylov, A.M., \& Petrov, N.A. (2021). Features of Digital Transformation of Modern Banking Transactions. Lecture Notes in Networks and Systems, 133, 673-681. Switzerland. https://doi.org/10.1007/978-3-030-47458-4_77

18. Rizzo, M. (2014, April 10). Digital Finance: empowering the poor via new technologies. http://www.worldbank.org/en/news/feature/2014/04/10/digital-financeempowering-poor-new-technologies

19. Galera-Zarco, C., Opazo-Basaez, M., Maric, J., \& Garcia-Feijoo, M. (2020). Digitalization and the inception of concentric strategic alliances: a case study in the retailing sector. Strategic Change, 29(2), 165-177. https://doi.org/10.1002/jsc.2319

20. Fedorkova, K. (2018). Importance of Financial Aspects of a Company Crisis Management in Slovakia. Marketing and Branding Research, 5, 8-22. http://dx.doi.org/10.33844/mbr.2018.60439

21. Kurniawan, Y., \& Hiererra, S. (2016). Information systems design for sustainability financial services company using enterprise architecture framework: A case study approach. 4th International Conference on Information and Communication Technology ICoICT. https://doi.org/10.1109/ICoICT.2016.7571904

22. Vovchenko, N.G., Holina, M.G., Orobinskiy, A.S., \& Sichev, R.A. (2017). "Ensuring financial stability of companies on the basis of international experience in construction of risks maps, internal control and audit". European Research Studies Journal, 20(1), 350-368. https://doi.org/10.35808/ersj/623

23. Nonaka, H., Kubo, D., Makoto Kimura, T.H., Ota, T., \& Masuyama, S. (2014). Correlation analysis between financial data and patent score based on HITS algorithm. IEEE International Technology Management Conference ITMC. https://doi.org/10.1109/ITMC.2014.6918607

24. Fetai, B. (2015). "Financial integration and financial development: Does financial integration matter?". European Research Studies Journal, 18(2), 97-106. https://doi.org/10.35808/ersj/447

25. Fauzi, A.A., \& Sheng, M.L. (2020). "The digitalization of micro, small, and mediumsized enterprises (MSMEs): an institutional theory perspective". Journal of Small Business Management. https://doi.org/10.1080/00472778.2020.1745536

26. Ming, L. (2011). Capacity of product design, financial service and performance of small and medium manufacturing enterprises. International Conference on Computer and Management, CAMAN, 285. https://doi.org/10.1109/CAMAN.2011.5778819 